\title{
Application of vapor phase corrosion inhibitors for contaminated environments
}

\author{
Behzad Bavarian ${ }^{1, *}$, Aline B. Avanessian ${ }^{1}$, Reza Yekani $^{1}$, Lisa Reiner $^{1}$, Ivana Radic Borsic ${ }^{2}$, and Boris Miksic ${ }^{3}$ \\ ${ }^{1}$ Dept. of Manufacturing Systems Engineering \& Management College of Engineering and Computer Science California State \\ University, Northridge, CA 91330, USA \\ ${ }^{2}$ Cortec Corporation Europe, Ivana Lucica 5, 10000 Zagreb, Croatia \\ ${ }^{3}$ Cortec Corporation, 4119 White Bear Parkway, St. Paul, MN 55110, USA
}

\begin{abstract}
Availability and accessibility to clean water for industrial applications such as hydrotesting and hydrostatic testing of pipelines, vessels, and plumbing distribution systems has been a challenging task especially when the job sites are in remote locations. When contaminated water is used in these tests, corrosion of the metallic components of the systems, during and after testing become a major concern. Vapor-phase corrosion inhibitors (VCI), can be added to water in small concentrations to prevent corrosion during testing, during wet storage and after testing. These inhibitors are to prevent corrosion of metallic components in three phases, within the solution, at the water line, and above the water line. Three commercially available corrosion inhibitors were evaluated in this investigation. Laboratory studies are presented in this paper, showed the effectiveness of VCI products in both fresh and salt water applications. Average corrosion rate dropped from $\sim 10$ mpy for salt solution to less than 1-1.6 mpy when various inhibitors was added. The effectiveness of these inhibitors is remarkable in the fresh water (less than 0.4 mpy). Exposure of the steel samples to these inhibitors did not show any loss in mechanical properties. Both strength and ductility of the low carbon steel samples was maintained.
\end{abstract}

\section{Introduction}

Hydrostatic pressure testing of metallic equipment such as pipes, vessels and valves is an important method for quality control of parts, after production and during use in order to demonstrate the strength and integrity of the systems [1]. This test is a key part of ensuring that they are fit for purpose depending on factors such as contact time, chemicals used, oxygen and bacteria. Water is the most common media to be used in this test, however, corrosion of the metal during and after testing is a concern because the water is typically left in pipelines from a couple of days to months. The challenge is that hydrostatic test water is corrosive, and disposal of the water is costly. Hydrostatic test water contains microorganisms, oxygen and sediment that are known to accelerate corrosion progression. Also, because of the large volume of water used, treatment can be very expensive. In some cases, equipment that has gone through a hydrostatic test will also be stored for future use or shipped long distances. This storage may take place while water is still inside the equipment (wet storage) or even after draining [2-4]. Therefore, a pipeline undergoing a hydrostatic test may become quite vulnerable to general corrosion, crevice and pitting corrosion, stress corrosion cracking, differential aeration corrosion or microbially induced corrosion [2]. Corrosion caused by any one or combination of these

*Corresponding author: Bavarian@scun.edu mechanisms may reduce pipeline service life and in extreme cases make it unfit for purpose.

With fresh water resource growing shortage, it is noteworthy to utilize seawater instead of fresh clean water as supplement water of recirculating cooling water system [2-3]. Seawater as industrial circulating cooling water can relieve the contradiction between shortage of fresh water and rapid development of industries effectively [4]. But seawater is an electrolyte solution with multiple salts, mainly $3.0 \% \sim 5.0 \%$ sodium chloride, $\mathrm{pH}$ value about 8 , and dissolving a certain oxygen [1]. Due to its chemistry, seawater easily corrode pipeline and heat exchanger in the recirculating cooling water system. So, the key of seawater utilization is to solve piping and equipment corrosion problem in the seawater environment by modifying its chemistry with corrosion inhibitors addition.

Corrosion and corrosion inhibition of steel have received enormous attention in recirculating cooling water system [5-7.] The common methods to control and prevent metal equipment corrosion have using resistant material, using cooling water anticorrosion coating, increasing $\mathrm{pH}$ value of the cooling water operation and adding corrosion inhibitor [6-9]. Among these methods using resistant material can protect metal equipment effectively, but the previous expenses is too high. The technology of anticorrosion coating method is complex and this method applies to local anticorrosion in the system. Increasing cooling water $\mathrm{pH}$ value makes mild 
steel deactivation easily. Adding corrosion inhibitor can protect the whole system and it is economical and practical.[7].

The development of seawater corrosion inhibitor undergoes from inorganic to organic, from single to compound, from single inhibition type to mixed inhibition type and other electrochemistry method combination process [8]. Many organic molecules exhibit high anticorrosion potential, but they pollute the environment during their synthesis and applications [79]. The effect of single seawater corrosion inhibitor is unsatisfactory in general, so two types or several types compound coordinate use to improve inhibition efficiency.

To control corrosion and bacterial growth in the pipeline during hydrostatic pressure test and future storage, the test water may be treated with corrosion inhibitors and other chemical compounds to manage and control corrosion activities. Commonly used chemicals are biocides which kill and prevent the formation and growth of bacteria and other organisms in the seawater, corrosion inhibitors used to inhibit general corrosion when residual oxygen is available and oxygen scavengers used to reduce the amount of oxygen available for corrosion and bacterial growth. After the completion of a hydrostatic test, the water must be discharged, often with environmental considerations [8]. Different classes of corrosion inhibitors may be used to protect systems from corrosion, including inorganic or organic. Inorganic inhibitors include nitrites, phosphorous based and others. Organic inhibitors are the products formulated from molecules constructed from $\mathrm{C}, \mathrm{H}, \mathrm{O}$, or $\mathrm{N}$ atoms. Vapor-phase corrosion inhibitors (VCI) described in this paper are organic based blends. The mechanism of the corrosion protection of organic inhibitors includes the formation of a thin, sometimes monomolecular layer on the metal, which is a protective barrier to aggressive ions [4-5]. In the majority of cases, organic components form a physical bond with the metal substrate. Formulations can include components with other functionalities for added protective capabilities. The main difference of the VCI products versus non VCI products, is the presence in the formulation of an ingredient with moderately high vapor pressure that can prevent corrosion in the vapor space without applying VCI directly to the metal surface [9-10]. The typical examples of this class are organic amines and their salts with carboxylic acids (aminocarboxylates). The advantage of VCI are that the volatilized molecules can reach hard to-reach spaces. When they reach the metal, VCI attach to it by the active group, creating a strong physisorption mechanism.

\section{Experimental procedure}

The main objective of this investigation was to study corrosion behavior of steel samples used as base material for pipelines to demonstrate effective corrosion protection of different vapor phase corrosion inhibitors. The choice of corrosion inhibitors for this study was made based on their functions and effectiveness in different aqueous solutions. VCI-A, VCI-B and VCI-C are water soluble products; have demonstrated to inhibit corrosion of low carbon steel during hydro-tests using fresh water. These inhibitors are combination of film formers and vapor corrosion inhibitors. The main ingredients are salts of amines and organic acids of different chemical structure and triazole. The main function of this product is formation of a protective film with some vapor corrosion inhibition action. All these inhibitors are biodegradable and surface modifiers.

The steel used in this study is a low-carbon carbon steel (UNS G10180) with a chemical composition ( $\mathrm{wt} \%$ ) of $0.14-0.22 \% \mathrm{C}, 0.3-0.65 \% \mathrm{Mn}, \leq 0.3 \% \mathrm{Si}, \leq 0.05 \% \mathrm{~S}$, $\leq 0.045 \% \mathrm{P}$, and the remainder Fe. The carbon steel samples were pre-treated prior to the experiments by polishing with silicon carbide paper $(240,320,400,600$, and fine polishing with 1.0 um Almina powder), degreased in acetone for 5 minute in ultrasonic bath, then rinsed with ethyl alcohol and dried in desiccator at room temperature. The corrosion inhibitors were three different USDA Biobased labeled (based on ASTM D6866, Organic carbon has $\mathrm{C}-\mathrm{H}$ bonds and often $\mathrm{C}-\mathrm{C}$ bonds) VCI-A, VCI-B and VCI-C, these corrosion inhibitors were remixed with different dosages $(0.5 \%$ or Crelation for an effective protection. The salt solutions were prepared based on $1.0 \mathrm{NaCl}$ or $3.5 \% \mathrm{NaCl}$ solutions. Corrosion behavior of the low carbon steel (UNS G10180 steel), were investigated exposed to the different three different corrosion inhibitors in salt solutions using electrochemical techniques, total immersion tests, and vapor-inhibiting ability (VIA, NACE TM 208-2018) [11]. Electrochemical polarization standards per ASTM-G61 (Cyclic polarization), Polarization resistance/Corrosion rate measurements, and electrochemical impedance spectroscopic techniques were used to evaluate the behavior of these inhibitors on the different alloys in different chloride solutions.

\section{Electrochemical Impedance Spectroscopy (EIS) Behavior}

The corrosion behavior of low carbon steel (UNS G10180 steel) were investigated using electrochemical impedance spectroscopy (EIS) in different salt concentrations. The experiments were conducted using commercially available systems for EIS and DC corrosion tests. Bode plots were created from the data obtained using the potentiostatic technique. By comparing the bode plots, changes in the slopes of the curves were monitored as a means of establishing a trend in the $\mathrm{Rp}$ value over time. To verify this analysis, the $\mathrm{Rp}$ values were also estimated by using a curve fitting algorithm on the Nyquist and Bode plots. In these plots, the $\mathrm{Rp}$ and $\mathrm{R}$ combined values are displayed in the low frequency range of the bode plot and the $\mathrm{R}$ value can be seen in the high frequency range of the bode plot. The diameter of the Nyquist plot is a measure of the $\mathrm{Rp}$ value. During this investigation, changes in the polarization resistance $(\mathrm{Rp})$ of these alloys were 
monitored to ascertain the degree of effectiveness for these inhibitors to lower corrosion rate.

The NACE TM 208-2018 Standard Test Method was also used to evaluate the vapor-inhibiting ability (VIA) of various forms of VCI. [11]. This laboratory test method evaluates the vapor-inhibiting ability (VIA) of various forms of VCI materials for temporary corrosion protection of ferrous metal surfaces. The VIA corrosion test method provides for standard conditions in a test jar of water-saturated, warm air without the presence of accelerating contaminants. The combination of (1) vapor transport across a gap containing air, water vapor and VCI, and (2) corrosion protection are evaluated in this test method. The VIA tests consist of four steps of sample conditioning or saturation for 20 hours at $22^{\circ} \mathrm{C}$, cooling cycle at $2^{\circ} \mathrm{C}$, pre-warming at $50^{\circ} \mathrm{C}$, followed by three hours at $22^{\circ} \mathrm{C}$ for specimen conditioning. After the last three hour conditioning period, the steel samples were inspected for visible water condensation. Following verification of water condensation on each sample, visual examination of the surface was done and microscopic observation was conducted to determine the corrosion rating for each sample. The corrosion criteria for rating steel specimens consist of grade 0 through grade 4 . To have a valid test, the control sample must have grade 0 ; samples with no inhibitor received worst grade. The control samples consistently rated a grade 0 for all VIA tests, therefore, validating the test method. Relative humidity and the temperature of each test jar were monitored by inserted sensors and data logging software. Post-test evaluation of surface condition of exposed samples using digital Light microscopy, scanning electron microscopy (SEM/EDS analysis) and XPS analysis.

\section{Experimental Results and Discussions}

Figures 1-3 show the polarization behavior for UNS G10180 steel in 1.0\% inhibitor (different VCI products) in different salt solutions. The most noticeable changes are the positive shift in the breakdown potential and expansion of the passive range for these alloys when inhibitors were added. These inhibitors showed to be an effective cathodic inhibitors. The inhibitor changed the reactivity by reducing the $\mathrm{pH}$ level, increased the passivation range significantly, and was beneficial in reducing localized corrosion damages. As demonstrated in these polarization curves, extension of the passive zone contributes to the stability of the protective oxide film over a wider electrochemical range, resulting in a more stable passive film, and shift of the critical pitting potential to higher levels.

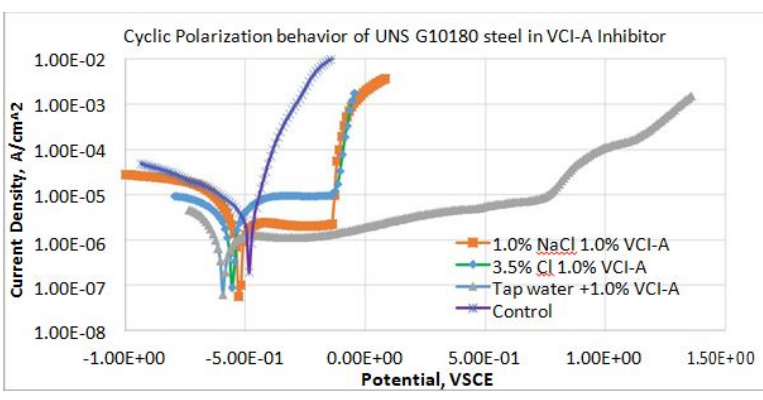

Fig. 1. Cyclic Polarization behavior of UNS G10180 steel in $1.0 \%$ VCI-A Inhibitor at different aqueous solutions.

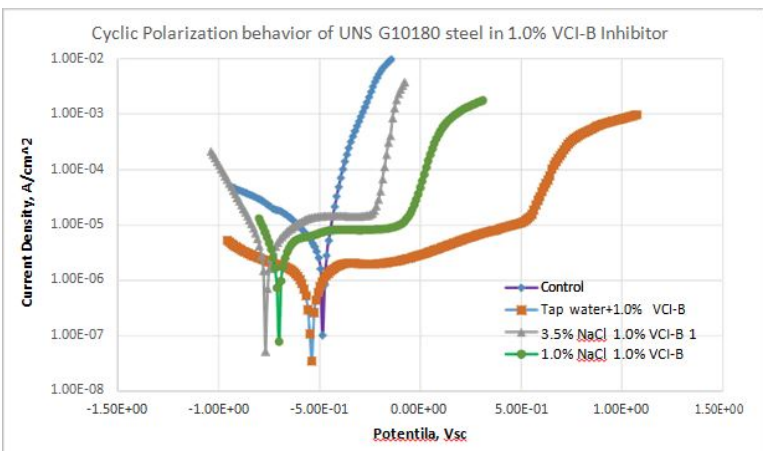

Fig. 2. Cyclic Polarization behavior of UNS G10180 steel in $1.0 \%$ VCI-B Inhibitor at different aqueous solutions.

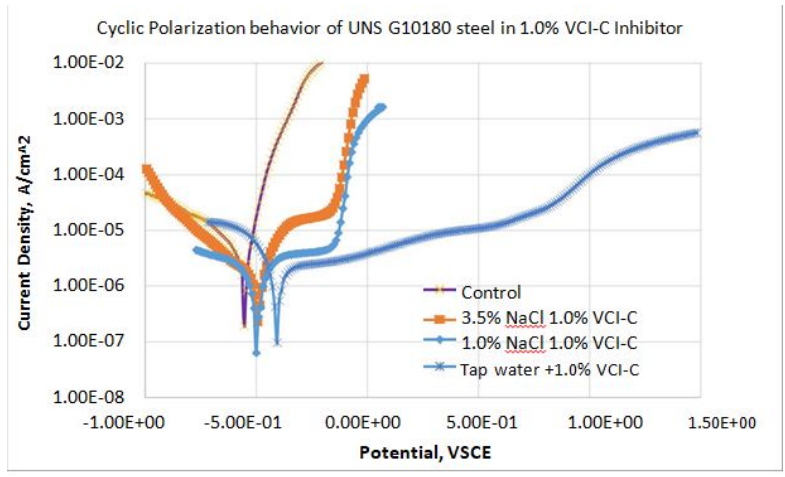

Fig. 3. Cyclic Polarization behavior of UNS G10180 in 1.0\% VCI-C Inhibitor at different aqueous solutions.

Corrosion rate measurements based on the linear polarization rate are shown in Figures 4-6. Effectiveness of these VCI products is confirmed in various water chemistries including fresh and salt water. Corrosion rate dropped from $\sim 10$ mpy for the salt solution to less than 1-2 mpy when various inhibitors was added. The effectiveness of these inhibitors was remarkable in the fresh water(less than 0.4 mpy). 


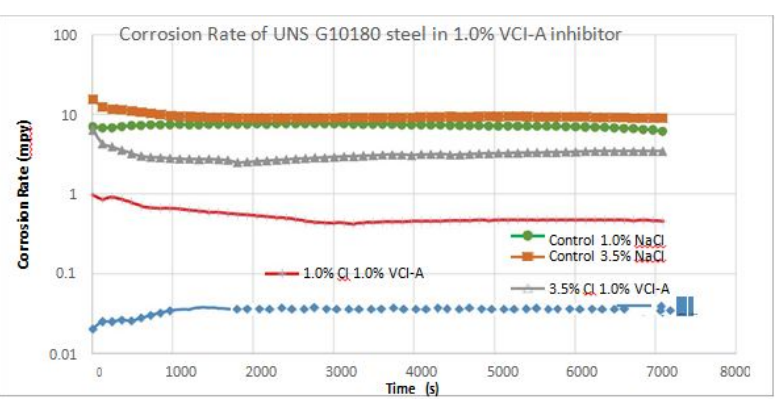

Fig. 4. Corrosion rate measurement (based on LPR) of UNS G10180 steel in 1.0\% VCI-A Inhibitor at different aqueous solutions.

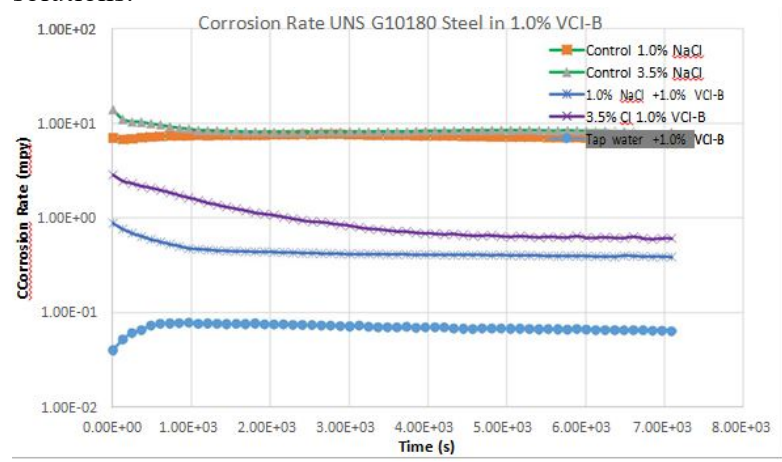

Fig. 5. Corrosion rate measurement (based on LPR) of UNS G10180 steel in 1.0\% VCI-B Inhibitor at different aqueous solutions.

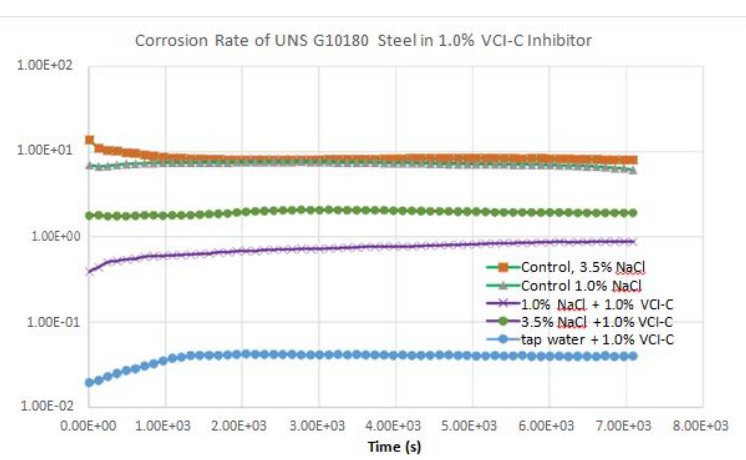

Fig. 6. Corrosion rate measurement (based on LPR) of UNS G10180 steel in 1.0\% VCI-C Inhibitor at different aqueous solutions.

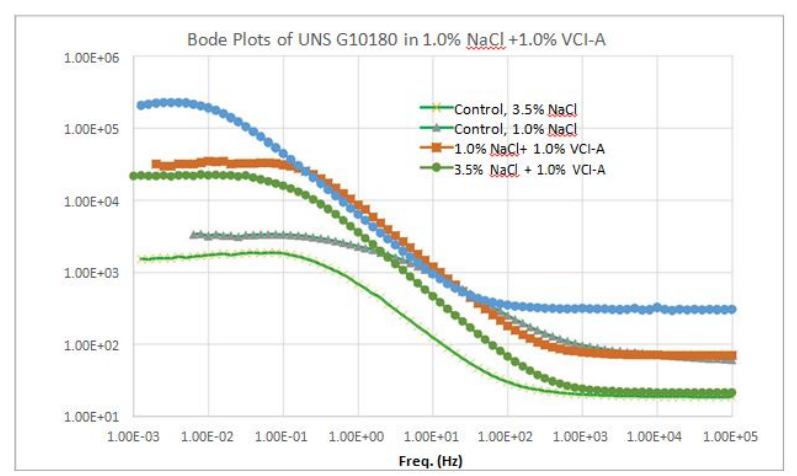

Fig. 7. EIS Bode plot of UNS G10180 steel in 1\% VCI-A Inhibitor at different aqueous solutions.

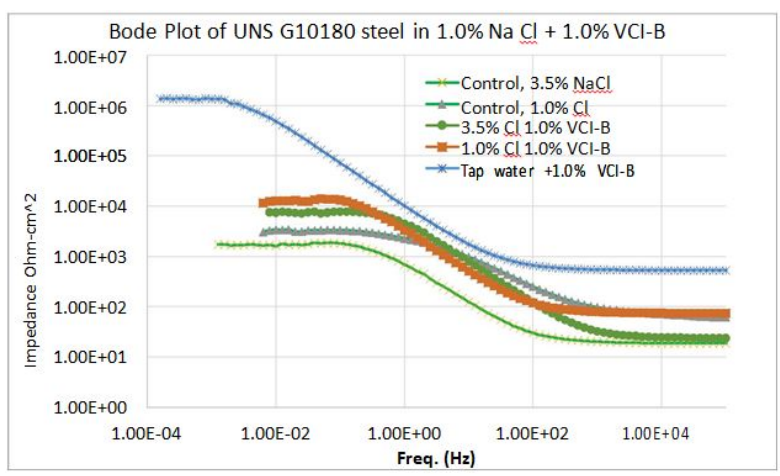

Fig. 8. EIS Bode plot of UNS G10180 steel in 1.0\% VCI-B Inhibitor at different aqueous solutions.

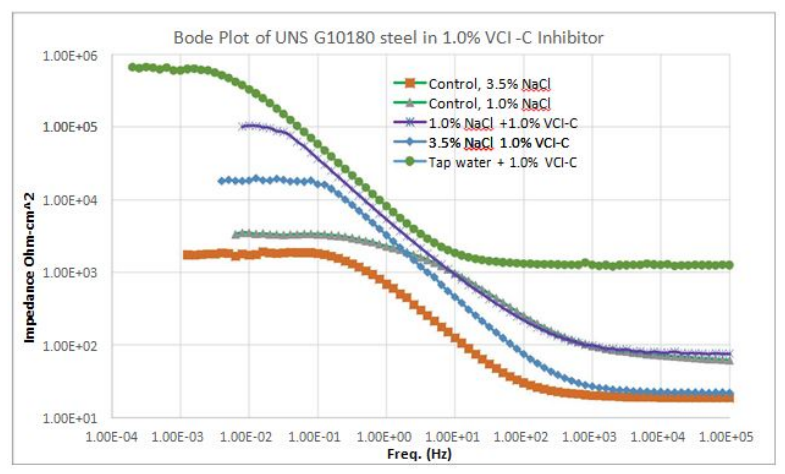

Fig. 9. EIS Bode plot of UNS G10180 steel in 1.0\% VCI-C Inhibitor at different aqueous solutions.

The corrosion behavior of low carbon steel low carbon steel were investigated using electrochemical impedance spectroscopy (EIS) in different salt concentrations, various Bode plots are shown in Figures 7-9. These results showed a significant increase in polarization resistance when inhibitors were added. Measured polarization resistance was jumped from 2000-3000 ohm-cm2 to more than 30,000 to 110,000 $\mathrm{ohm}-\mathrm{cm} 2$. These increase in polarization resistance is equivalent to significant decrease in corrosion rate.

Figure 10 summarizes the average measured corrosion rate by different electrochemical techniques. These results reaffirmed the necessity to add these inhibitors to testing media during hydro-testing.

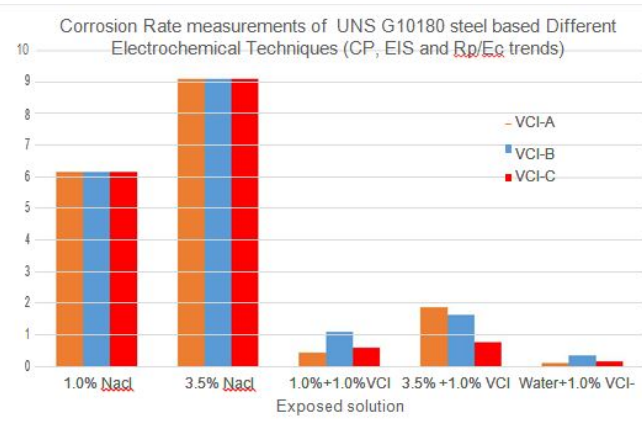

Fig. 10. Corrosion rate measurements of UNS G10180 steel using different Electrochemical Techniques (CP, EIS and $\mathrm{Rp} / \mathrm{Ec}$ trends) at different aqueous solutions.

This laboratory test method evaluates the vaporinhibiting ability (VIA) of these VCI products are shown 
in Figures 11-12. Samples were visually inspected and their surface conditions were documented after VIA tests were completed using optical digital microscopy and scanning electron microscope. Based on three set of VIA tests, the observation showed that the control had a grade 0 (severe pitting corrosion), while the addition of VCI-A, VCI-B and VCI-C had resulted to a significantly improvement to grade 3 (almost no corrosion attacks). These results showed that these inhibitors have a very strong vapor-inhibiting ability. Additionally, any leftover residue of hydro-testing solution in pipes will be beneficial and provide extra protection during storage period. Contrary to the stagnant wet condition that testing without inhibitor might cause.

Typical visual patterns for rating VIA test results

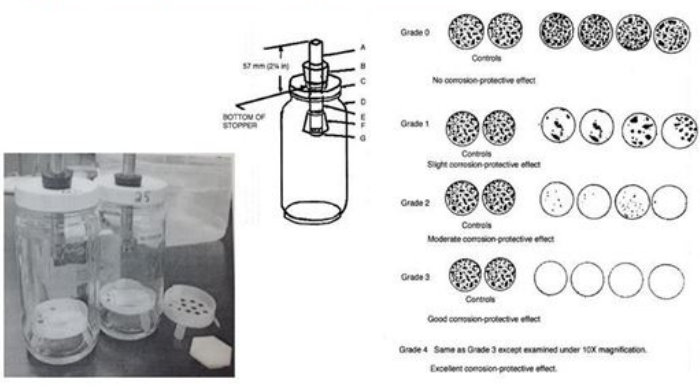

Fig. 11. Test setup and rating criteria for the NACE TM 2082018 Standard Test Method.
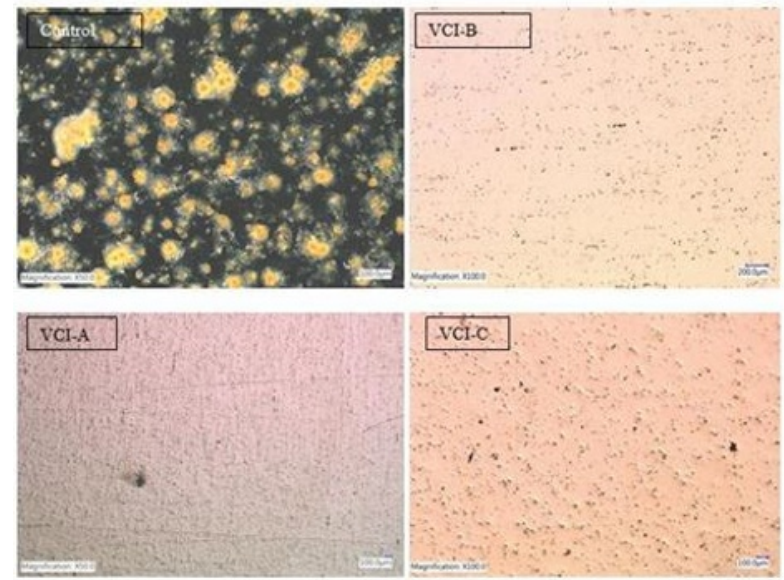

Fig. 12. Optical micrographs of the steel sample after VIA tests. These tests showed a significant improvement for VCIA, VCI-B and VCI-C compared to the Control sample.

VIA Rating: Control grade 0, VCI-A, VCI-B, VCI-C grade 3.
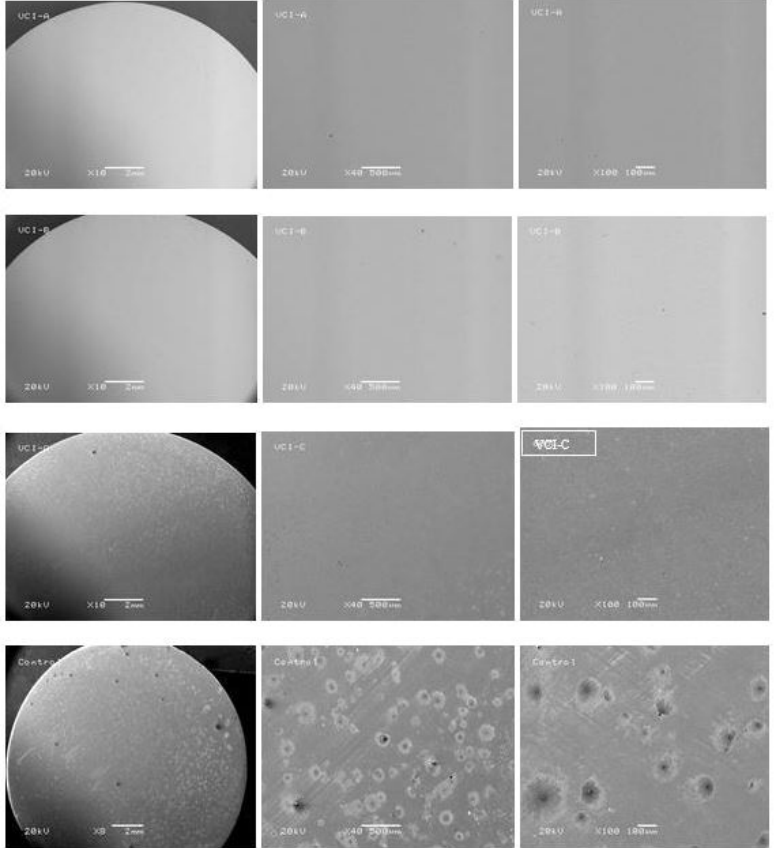

Fig. 13. SEM micrographs of steel sample after VIA tests. Superior performance for VCI-A, VCI-B and VCI-C were observed compared to the Control sample.

VIA Rating: Control grade 0, VCI-A, VCI-B, VCI-C grade 3.

The VIA visual observations are shown in Figure 11. The corrosion rating per TM-208 indicated that the control sample had Grade 0, while VCI-A, VCI-B and VCI-C rating were Grade 3. Optical micrographs of the surface condition of samples after VIA tests is shown in Figure 12. Figure 13 shows SEM micrographs of the steel sample after VIA tests. The high resolution SEM images show a significant improvement for VCI-A, VCI-B and VCI-C with no sign of any pitting corrosion.

Figure 14 shows the effects of different corrosion inhibitors on the mechanical behavior of low carbon steel. Tensile tests on the exposed samples after four week immersion tests indicated that the level of corrosion attacks were minimized, no sign of any deterioration in ductility of the exposed samples was detected.

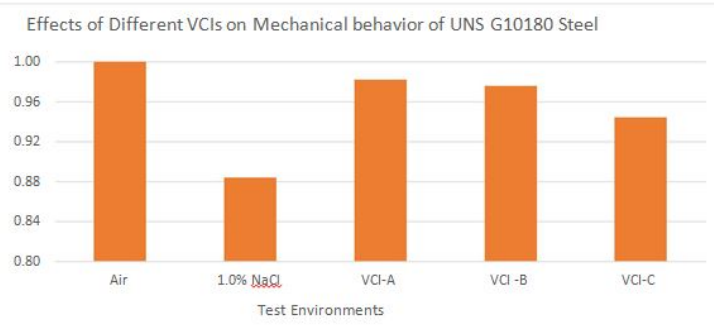

Fig. 14. Effects of different inhibitors on tensile ductility of UNS G10180 steel.

\section{Inhibitor Adsorption Mechanism}

The adsorption isotherm relationship between surface coverage and temperature for three VCI-A, VCI-B and VCI-C inhibitors on the surface of steel is shown in 
Figure 15. Adsorption energy was roughly $-21,520$ $\mathrm{J} / \mathrm{mol}$ for VCI-A inhibitor, $-22,950 \mathrm{~J} / \mathrm{mol}$ for VCIB inhibitor, adsorption energy was roughly $-24,970 \mathrm{~J} / \mathrm{mol}$ for the VCI-C inhibitor. This energy range is indicative of a good physical adsorption to the metal surface (generally a multilayer adsorption energy between 5,000 to $-50,000 \mathrm{~J} / \mathrm{mol}$ is defined as a physisorption mechanism, a weak, long range bonding. However, it can be seen that interaction of VCI-C with the steel surface is higher than other inhibitor, leading to better corrosion protection. XPS depth profiling analysis showed $\sim 60-65 \mathrm{~nm}$ of adsorbed inhibitor on the exposed samples, indicating that multilayer adsorption of inhibitors molecules to the steel surfaces. Therefore, Brunauer Emmett Teller Model (BET Model) is more realistic adsorption model than the monolayer Langmuir model for this case [1214]. But for the adhesion energy calculation between inhibitor molecules and metal surface, it is appropriate to use the monolayer Langmuir model [15].

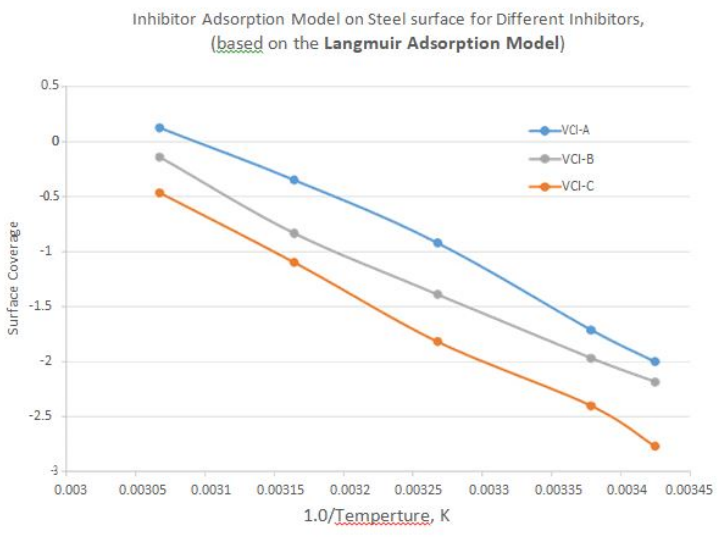

Fig. 15. The adsorption isotherm relationship between surface coverage and temperature for different VCI inhibitors on the surface of steel. Adsorption energy was roughly $-21,500$ and $22,950 \mathrm{~J} / \mathrm{mol}$ for the VCI-A and VCI-B inhibitors, while, adsorption energy was roughly $-24,970 \mathrm{~J} / \mathrm{mol}$ for VCI-C inhibitor.

\section{Conclusion}

This investigation demonstrated that VCI additives can prevent corrosion of carbon steel during hydro-testing and after. When necessary, other VCI products can complement hydro-test additives for long term storage. Electrochemical Cyclic polarization showed formation of a stale passive range when these inhibitors were added to environments. Effectiveness of VCI products is confirmed in various water chemistries including fresh and salt water. Corrosion rate dropped from $\sim 10$ mpy for salt solution to less than 1-2 mpy when various inhibitors was added. The effectiveness of these inhibitors was remarkable in the fresh water (less than 0.4 mpy). Tensile tests post immersion tests did not show any loss in mechanical properties of the exposed samples. Both strength and ductility of the low carbon steel samples was maintained. Adsorption energy was roughly $-21,520 \mathrm{~J} / \mathrm{mol}$ for VCI-A inhibitor, $-22,950$ $\mathrm{J} / \mathrm{mol}$ for VCIB inhibitor, adsorption energy was roughly $-24,970 \mathrm{~J} / \mathrm{mol}$ for the VCI-C inhibitor, indicating a strong physisorption mechanism.

Results indicated that these biodegradable, environmentally friendly VCI additives have low toxicity level and waters containing these VCI products remain safe for many species, allowing discharge according to local specifications.

\section{References}

1. A.R. Duffy, M.G.McClure, W.A. Maxey, T.J. Atterbury, Study of Feasibility of Basing Natural Gas Pipeline Operating Pressure on Hydrostatic Test Pressure, American Gas Association, Inc. (1968)

2. J.F.Kiefner, W.A. Maxey, R.J. Eiber, A Study of the Causes of Failure of Defects That Have Survived a Prior Hydrostatic Test, Pipeline Research Committee, American Gas Association, NG-18 Report No. 111 (1980)

3. N.P.Zuk, Course of Theory and Protection from Corrosion, Moscow Metallurgy (1976)

4. S.Z.Levin, 2nd European Symposium on Corrosion Inhibitors, Ferrara, Italy

5. Society of Petroleum Engineers Inc, Use of Preservation Chemicals Following Hydrostatic Testing of Pipelines (2017)

6. X. XU, Hydrotest Water Specification and Integrity Considerations, www.corrosionguru.com

7. M. G. Kadhim, M. Albdiry, A Critical Review on Corrosion and its Prevention in the Oilfield Equipment, Journal of Petroleum Researc \& Studies (2017)

8. J. Holden, A. Hansen, A. Furman, R. Kharshan, E. Austin, Vapor Corrosion Inhibitors in Hydro-testing and Long Term Storage Applications, NACE Corrosion 2010 Conference (2010)

9. B.A.Miksic, Reviews on Corrosion Inhibitors Science and Technology, NACE (1993)

10. Y.S. Sartry. Corrosion Inhibitors. Principles and Applications, Wiley \& Sons Ltd, (1998)

11. NACE TM 208-2018 Standard Test Method Laboratory Test to Evaluate the Vapor Inhibiting Ability of Volatile Corrosion Inhibitor Materials for Temporary Protection of Ferrous Metal Surfaces (2018)

12. B. Bavarian, L. Reiner, H. Youssefpour, Vapor Phase Inhibitors to Extend the Life of Aging Aircraft, NACE 2005 Conference, (2005)

13. B. Bavarian, J. Zhang, L. Reiner, SCC and Crevice Corrosion Inhibition of Steam Turbines ASTM A470 and AA7050 Al-alloys using VCI, NACE 2012 Conference (2012)

14. B. Bavarian, L. Reiner, J. Holden, B. Miksic, Amine Base Vapor Phase Corrosion Inhibitor Alternatives to Hydrazine for Steam Generating Systems and Power Plants, NACE 2018 Conference (2018)

15. L.Czepirski, M. R. Balys, E. Komorowska-Czepirska, Some generalization of Langmuir adsorption isotherm, Internet Journal of Chemistry 3 (14), ISSN 10998292 (2000) 